\title{
Umberto Eco, Jorge Luís Borges e uma Formulação Literária do Conceito de INTERTEXTUALIDADE
}

\section{Marcelo Pacheco Soares ${ }^{1}$}

RESUMO: A intertextualidade representa um fenômeno estético-literário que ocorre com assiduidade em toda a literatura moderna desde o Renascimento, movimento intertextual por definição. O presente artigo pretende investigar como as produções literárias do escritor e semiólogo italiano Umberto Eco e do argentino Jorge Luís Borges tecem, no século XX, teorias a respeito deste fenômeno, notadamente por meio da metáfora dos espelhos.

PALAVRAS-CHAVE: intertextualidade; Umberto Eco; Il nome della rosa; Jorge Luís Borges; Ficciones; espelho. 
ABSTRACT: L'intertestualità rappresenta un fenomeno estetico-letterario che spesso si ritrova in tutta la letteratura moderna fin dal Rinascimento, a sua volta movimento intertestuale per definizione. Il presente articolo esamina come le produzioni letterarie dello scrittore e semiologo italiano Umberto Eco e dell'argentino Jorge Luís Borges elaborano teorie su questo fenomeno, nel Novecento, mediante la metafora degli specchi.

PAROLE CHIAVE: intertestualità; Umberto Eco; Il nome della rosa; Jorge Luís Borges; Ficciones; specchio.

ABSTRACT: The intertextuality represents an aesthetic and literary phenomenon which happens frequently in the whole modern literature since Renaissance, movement which was intertextual by definition. The present article intends to investigate how the literary productions of Italian writer and semiologist Umberto Eco and of Argentinean Jorge Luís Borges compose, in the $20^{\text {th }}$ century, theories about this phenomenon, mainly through the metaphor of the mirrors.

KEYWORDS: intertextuality; Umberto Eco; Il nome della rosa; Jorge Luís Borges; Ficciones; mirror. 
Protendendo il lume in avanti mi spinsi nelle stanze seguenti. Un gigante di proporzioni minacciose, dal corpo ondulato e fluttuante come quello di un fantasma, mi venne incontro.

"Um diavolo!" gridai e poco mancò mi cadesse il lume, mentre mi voltavo di colpo e mi rifugiavo tra le braccia di Guglielmo. Questi mi prese il lume dalle mani e scostandomi si fece avanti con una decisione che mi parve sublime. Vide anch'egli qualcosa, perché arretrò bruscamente. Scoppiò a ridere.

"Veramente ingegnoso. Uno specchio!"

"Uno specchio?"

"Sì, mio prode guerriero. Ti sei lanciato con tanto coraggio su un nemico vero, poco fa nello scriptorium, e ora ti spaventi de fronte alla tua immagine. Uno specchio, che ti rimanda la tua immagine ingrandita e distorta."

(ECO, 1995, p. 175-6) 
Este excerto de Il nome della rosa, de Umberto Eco, refere uma cena que se desenvolve no Edificio - alcunha pela qual é conhecida a construção que abriga (ou esconde) a biblioteca do mosteiro medieval - numa das noites em que o frei Guglielmo da Baskerville e o seu jovem pupilo Adso da Melk, narrador do romance, tentam desvendar os segredos que aquelas paredes labirínticas encerram. O espelho deformante, cuja presença, num momento inicial, é ocultada pela escuridão do lugar sem que isso amaine os seus efeitos, exerce o papel de fazer crer verdade a quimera de que seres sobrenaturais guardam os segredos da coleção de livros, com o propósito de afastar dali leitores inconvenientes, um ardil que, potencializado pelo receio que se apossa naturalmente dos que entram às escondidas num lugar proibido, provoca efetivamente nos moradores da abadia os resultados almejados, conforme já ficara manifesto no diálogo travado no dia anterior entre Guglielmo e o mestre vidreiro local Nicola de Morimondo:

"Però laggiù”, e accennò all'Edificio, “i segreti della scienza sono ben difesi da opere di magìa..."

"Sì?”, disse Guglielmo ostentando indifferenza. "Porte sbarrate, divieti severi, minacce, immagino."

"Oh no, di più..."

"Cosa per esempio?"

"Ecco, io non so con esattezza, io mi occupo di vetri e non di libri, ma nell'abbazia circolano storie... strane...”

"Di che genere?"

"Strane. Diciamo, di un monaco che nottetempo ha voluto avventurarsi in biblioteca, per cercare qualcosa che Malachia non aveva voluto dargli, e ha visto serpenti, uomini senza testa, e uomini con due teste. Per poco non usciva pazzo dal labirinto...” (ECO, 1995, p. 97)

Apesar do sucesso alcançado até então por este estratagema, basta o reconhecimento, efetuado por Guglielmo, de que o diavolo com o qual Adso se espanta nada 
mais é do que o próprio seminarista refletido em um espelho deformante para que seja desvelado o embuste, para que o conflito se desfaça e o terror do rapaz seja substituído pelo riso do seu mestre.

A dialética em que baseia esta passagem da sua trama medieval, Umberto Eco (ECO, 1989, p. 17) a teoriza no ensaio "Sobre os espelhos", no qual o escritor italiano verifica que, "para usarmos bem o espelho, precisamos, antes de mais nada, saber que temos um espelho à nossa frente"; ideia aprimorada linhas à frente (ECO, 1989, p. 27), onde se acrescenta a peculiaridade deste objeto no contexto referido: "Se não sabemos nem que é espelho, nem que é deformante, então nos encontramos numa situação de engano perceptivo normal". O célebre equívoco que condena Narciso à morte seria a identificação arquetípica deste logro. Por isso, estes leitores vorazes que os dois personagens representam desempenharão plenamente a sua função de interpretantes, após se conscientizarem de que lidam com um espelho; ademais, um espelho deformante. Deste modo, já páginas mais adiante, Guglielmo e Adso conseguirão embrenhar-se nos mistérios do finis Africae, a sala secreta da biblioteca, para enfim lerem o livro que lhes era interdito:

Fummo in breve alla stanza dello specchio, ormai preparati al gioco deformante che ci attendeva. Alzammo le lampade e illuminammo $i$ versetti che sovrastavano la cornice, super thronos viginti quatuor... Ormai il segreto era chiarito: la parole quatuor ha sette lettere, occorreva agire sulla q e sulla $r$.

(...)

...quando fu spinta in avanti, la q fece udire come uno scatto secco, $e$ lo stesso accadde quando Guglielmo agi sulla r. L'intera cornice dello specchio ebbe come un sobbalzo, e la superficie vitrea scattò all'indietro. Lo specchio era una porta, incardinata sul lato sinistro. Guglielmo inserì la mano nell'apertura che si era creata tra il bordo destro e il muro, e tirò verso di sé. Cigolando la porta si aprì verso di noi. Guglielmo si insinuò nell'apertura e io scivolai dietro di lui, il lume alto sopra la testa.

(...)

...eravamo penetrati nel finis Africae. (ECO, 1995, p. 462-3) 
Reparemos: não é para dentro do espelho que os protagonistas deslizam; não é como Alice que eles agem, a adentrar a superfície refletora para consequentemente fazer parte dela, "vivendo a imagem virtual como se fosse real" (ECO, 1989, p. 31), o que Umberto Eco mesmo definiria como uma situação alucinatória. Em uma cena cuja referência imediata é justamente a circunstância-chave vivida pela personagem das narrativas infantis de Lewis Carroll, Adso acompanha Guglielmo para perscrutar o que acontece, não no interior do reflexo, mas atrás do espelho, a fim de investigar o que os seus efeitos deformantes ocultam. Aqui, o frade e o seu jovem aprendiz se revelam mais do que tão somente leitores ingênuos, como a própria Alice a interagir com os mundos maravilhosos que ela criava; Guglielmo e Adso representam, antes, o ato de ler em sua forma mais científica, pesquisando com apuro a estrutura do fazer literário, os bastidores do saber, e não apenas julgando os resultados do todo final da composição artística.

Assim, longe está de ser fortuito que a penetração através da abertura antes ocupada pelo espelho represente a deixa que encaminha para o capítulo-clímax da trama, em que os enigmas serão desvendados. Aliás, a esta altura, frei Guglielmo, em conversa com Adso, já tivera a oportunidade de referir uma possível aproximação de ordem metodológica entre o ato de ler e a ação de examinar pistas inerente ao trabalho do detetive, conforme afiançara na importante sentença: "I libri non sono fatti per crederci, ma per essere sottoposti a indagine” (ECO, 1995, p. 319). E seria desnecessário asseverar que o trabalho desenvolvido pelos ensaístas literários deve ser movido precisamente por esta curiosidade investigativa.

\section{Borges e o espejo fiel de "A Biblioteca de Babel"}

A escrita de Il nome della rosa (e, especialmente, a sua pós-escrita) evidencia as principais fontes em que o Umberto Eco bebeu em seu processo de composição do texto, dentre as quais encontramos, de modo bastante evidente, o argentino Jorge Luís Borges. O maior indício desta influência é o monge nomeado Jorge de Burgos, numa alusão evidente ao escritor sul-americano. Cego igual a Borges, este personagem de 
Il nome della rosa é delineado como alguém capaz de "muoversi e parlare come se possedesse ancora il bene della vista" (ECO, 1995, p. 86); e não é precisamente esta competência o que nos surpreende em Borges que escreve após a evidenciação da sua deficiência visual? Mas a característica que mais nos chama a atenção no personagem umbertiano é, em semelhança ao dado biográfico de Borges, a profunda afinidade entre o mal-humorado ancião cego e a vasta coleção de livros do mosteiro. É mesmo Eco (ECO, 1985, p. 26) quem reconhece: "Eu queria um cego como guardião de uma biblioteca (o que me parecia uma boa ideia narrativa) e biblioteca mais cego só pode dar Borges." Assim, segundo a narração de Adso, o Jorge criado pelo italiano "era insomma la memoria stessa della biblioteca" (ECO, 1995, p. 136).

Mas o ponto fulcral da nossa comparação entre o romance de Eco e a obra de Borges pode ser apreciado nas similitudes entre a biblioteca da abadia e a arquitetura da Biblioteca de Babel (encontrada no conto homônimo), erguida da seguinte maneira pelas letras borgianas:

El universo (que otros llaman la Biblioteca) se compone de un número indefinido, y tal vez infinito, de galerías hexagonales, con vastos pozos de ventilación en el medio, cercado por barandas bajisimas. Desde cualquier hexágono, se ven los pisos inferiores y superiores: interminablemente. La distribuición de las galerías es invariable. Veinte anaqueles, a cinco largos anaqueles por lado, cubren todos los lados menos dos; su altura, que es la de los pisos, excede apenas la de un bibliotecario normal. Una de las caras libres da a un angosto zaguán, que desemboca en otra galería, idéntica a la primera y a todas. A izquierda y a derecha del zaguán hay dos gabinetes minúsculos. Uno permite dormir de pie; otro, satisfacer las necesidades fecales. Por ahí pasa la escalera espiral, que se abisma y se eleva hacia lo remoto. En el zaguán hay un espejo, que fielmente duplica las apariencias. Los hombres suelen inferir de ese espejo que la Biblioteca no es infinita (si lo fuera realmente a qué esa duplicación ilusoria?); yo prefiero soñar que las superficies bruñidas figuran y prometen el infinito... La luz procede de unas frutas esféricas que llevan el nombre de lámparas. Hay dos en cada hexágono: transversales. La luz que emiten es insuficiente, incesante. (BORGES, 1956, p. 89-90) 
O método empregado por Borges para apresentar a Biblioteca de Babel está regulado por um discurso que descreve sem circunlóquios e, deste modo, impetra o seu objetivo de imediato, sintomatizando a peculiar característica desta edificação: apesar do número impreciso de galerias que a compõem e da sua presumível infinidade (o que deveria potencializar o seu aspecto labiríntico), a circunstância de, a partir de cada hexágono, ser possível enxergar simultaneamente todos os andares superiores e inferiores, transforma este prédio em um labirinto cujos caminhos são expostos, um labirinto que o visitante pode observar em toda a sua amplitude, ou seja, a Biblioteca de Babel é um labirinto que paradoxalmente não oferece objeção a um mapeamento.

Por outro lado, do Edificio (conforme, lembramos, é assim conhecida a biblioteca do mosteiro, em outra clara alusão ao arranha-céu borgiano) a visão obtida pelo leitor será construída de forma gradativa, enquanto, página a página, Guglielmo e Adso desvelam os seus segredos, ou seja, o percurso se expõe na medida em que andamos pelo seu interior, como ocorre nos labirintos habituais. Sua composição rememorará a Biblioteca de Babel - o próprio Eco (ECO, 1985, p. 47) define o seu labirinto como uma rede que "não tem centro, não tem periferia, não tem saída, porque é potencialmente infinito", o que nos remete à construção borgiana - mas não seguirá exatamente o mesmo projeto, já que a regularidade desta, formada por galerias hexagonais idênticas, dará lugar, no romance do escritor italiano, a outras formas geométricas quantitativa e qualitativamente diversas, como fica claro na recapitulação feita pelo próprio Guglielmo de um pequeno espaço que Adso e ele haviam percorrido: "Cinque stanze quadrangolari o vagamente trapezoidali, con una finestra ciascuna, che girano intorno a una stanza eptagonale senza finestre, a cui sale la scala" (ECO, 1995, p. 174).

A oposição entre as duas arquiteturas surge representada na desigualdade dos espelhos que encontramos em cada uma das duas bibliotecas: na criação de Umberto Eco, como testemunhamos, Guglielmo e Adso se deparam com um espelho deformante; em contrapartida, no saguão da Biblioteca de Babel, hay un espejo, que fielmente duplica las apariencias. Ora, o espelho, imbuído de cargas semânticas específicas, é comumente considerado uma alegoria dos mecanismos miméticos próprios da Literatura. Assim, sua presença em bibliotecas, onde se lhes oferece a ocasião de refletirem obras literárias, eleva-os oportunamente à metáfora não mais tão somente da escrita, 
mas ainda da re-escrita, da re-flexão; de fenômenos intertextuais, portanto.

Não tememos defender, inclusive, que a Biblioteca de Babel figura entre as mais perfeitas metáforas criadas na literatura mundial para conceber o fenômeno da intertextualidade. A possibilidade de, a partir de qualquer ponto, enxergar a Biblioteca em sua totalidade coíbe o isolamento que os livros habitualmente sofrem, enclausurados nas estantes de uma biblioteca comum (especialmente aquelas que possuem corredores como os do Edificio da abadia, construídos para antes censurar do que para democratizar o conhecimento). O espelho no saguão, por sua vez, justifica a infinidade para baixo dos andares que já crescem babélicos para cima e, por consequência, não permite que qualquer livro exista sem que seja duplicado. As duas imagens (a comunicação entre todos os livros e a duplicação de cada um deles) metaforizarão justamente o que se conhece por intertextualidade.

A justificativa teórica para a eleição da Biblioteca de Babel como alegoria de processos intertextuais, com o crescimento dos seus andares infinitamente para cima e, em consequência do espelho, também para baixo (em um desenvolvimento, portanto, simultâneo), encontra-se na afirmativa de que Borges (BORGES, 1974, p. 138) lança mão no artigo "Kafka e seus precursores", por ocasião da análise da obra do escritor tcheco, dando conta de que "cada escritor cria os seus precursores". Ou seja, o surgimento de um livro novo nos andares últimos da Biblioteca é o que gera o reflexo no espelho do saguão de sua obra precursora nos andares abaixo do espelho. A crença na infinidade da Biblioteca de Babel também encontra eco (com o perdão do jogo de palavras) nas ideias proferidas sobre a coleção de livros da abadia, já que, segundo descreve Malachia, responsável pelo lugar, "la biblioteca affonda la sua origine nel profondo dei tempi" (ECO, 1995, p. 83), o que lhe confere também uma natureza genesíaca.

É evidente que a preconizada fidelidade deste espelho colocado no saguão poria em xeque nossa defesa de que se trata, aqui, de uma metáfora da conexão intertextual entre obras distintas. No entanto, a leitura de outro conto de Borges, também publicado no volume Ficções, "Pierre Menard, autor de Quixote", em que o narrador-analista demonstra que um determinado trecho da escrita de Miguel de Cervantes, copiada ipsis verbis por um homem do século $\mathrm{XX}$, ganha significado distinto e configura-se, 
pois, em um novo texto, legitima que este espelho, ainda que fiel, deforme a obra original gerando uma nova, em função do contexto em que este reflexo estará inserido, já que, como já dissemos antes, a imagem divisada no espelho dependerá de quem o empunha. Em decorrência disso, declara a voz narrativa do conto sobre a coleção babélica: "No hay, en la Biblioteca, dos libros idénticos" (BORGES, 1956, p. 94). Aliás, em "A Loteria da Babilônia", há uma ideia ainda mais radical: "No se publica un libro sin alguma divergencia entre cada un de los ejemplares" (BORGES, 1956, p. 79), provavelmente porque cada exemplar será lido por indivíduos distintos, refletirá culturas que serão mais ou menos dessemelhantes, mas nunca efetivamente idênticas.

Caminhemos além: a expressão matemática Biblioteca $=$ universo hiperboliza esta metáfora, porque dá a entender a existência de um fio que interligue, direta ou indiretamente, todas as obras literárias. Não por acaso, a Biblioteca abriga inclusive os livros que tratam das "interpolaciones de cada libro em todos os libros" (BORGES, 1956, p. 94). Outrossim, parece evidente que o Edifício da abadia também ambiciona ser uma metonímia do mundo literário, como o próprio Eco revela em suas confissões em forma de Pós-Escrito a Il nome della rosa: "os livros falam sempre de outros livros e toda história conta uma história já contada" (ECO, 1985, p. 20). E reitera a seguir: "só se fazem livros sobre outros livros e em torno de outros livros" (ECO, 1985, p. 40). Tudo isso emerge após o conceito primeiro de intertextualidade ("todo texto se constrói como mosaico de citações, todo texto é absorção e transformação de um outro texto") ser cunhado por Julia Kristeva (KRISTEVA, 1974, p. 64), sob confessada influência da noção de dialogicidade textual proposta por Mikhail Bakhtin, cujas premissas estudadas, levadas a termo, resultam exatamente nesta complexa inter-relação entre todos os textos. A propagada morte do autor (desautorizando que se fale em intenção) e a consequente falta de ciência por parte desta agora mera categoria literária que se tornou o mesmo autor quanto à totalidade das relações intertextuais manifestadas na escritura seriam assim os fatores decisivos para a concepção deste volume único e sem limite de páginas que englobaria todas as obras existentes ou passíveis de existência, o que condiz com a conclusão de Roland Barthes (BARTHES, 1974, p. 77) de que "é isto o intertexto: a impossibilidade de viver fora do texto infinito".

A complexidade da rede de relações intertextuais que Borges e Eco defendem está 
também representada no conto "Tlön, Uqbar, Orbis Tertius", de autoria do escritor argentino. Aqui, o personagem Borges, em busca de um verbete enciclopédico a respeito de Uqbar, um país imaginário que ganha status de realidade pelo caráter científico do livro que o descreve, encontra algo ainda mais inusitado: Tlön, um planeta imaginário, criado por várias gerações de uma "sociedad secreta de astrónomos, de biólogos, de ingenieros, de metafísicos, de poetas, de químicos, de algebristas, de moralistas, de pintores, de geómetras... dirigidos por um oscuro hombre de genio" (BORGES, 1956, p. 20). O exame da literatura deste planeta nos proporciona duas revelações: a primeira é a de que, em Tlön, "no existe el concepto de plagio: se ha estabelecido que todas las obras son obra de un solo autor, que es intemporal y es anónimo" (BORGES, 1956, p. 28), tão atemporal e anônimo quanto aquele hombre de genio, detentor de todos os saberes, representação viva da própria enciclopédia na qual Borges realiza a sua pesquisa, que conduz a criação da realidade-ficção que circunda esta ficção de segundo grau; a outra revelação é a de que, dos livros de Tlön, "los de ficción abarcan un solo argumento, com todas las permutaciones imaginables" (BORGES, 1956, p. 28). Ou seja, todos os livros são um único e interminável Livro, cujos autores se consubstanciam num Autor singular, conforme conclui Eduardo Lourenço (LOURENÇO, 1984, p. 51): "O bibliotecário genial de Buenos Aires mediu como que a vacuidade dos livros e resumiu-a no mito de um Livro eterno e inacessível do qual todos procedem e ao qual todos reenviam". Obtemos, então, consentimento para qualquer proposta de leitura intertextual, inclusive, é claro, a que aqui exploramos entre Eco e Borges.

Assim, consideramos sempre que a Biblioteca de Babel está destinada à decifração, tal como a narração borgiana define Tlön: "Tlön será un labirinto, pero es un labirinto urdido por hombres, un labirinto destinado a que lo descifren los hombres" (BORGES, 1956, p. 35), um labirinto que sofrerá decifração já que, de acordo com o próprio conto de Borges, o mundo será Tlön; ou como defende o narrador e personagem de "Funes el memorioso": "tarde o temprano, todo hombre hará todas las cosas y sabrá todo" (BORGES, 1956, p. 129). Será precisamente por isso que a Biblioteca de Babel se mostrará aberta ao mapeamento, porque Literatura é um labirinto construído para ser decifrado. 


\section{Conclusão: o jogo dos espelhos e a leitura}

A construção do jogo de espelhos (o deformante de Eco e o fiel de Borges), criado pela comparação entre o conto "A Biblioteca de Babel" e o romance Il nome della rosa, revela, ainda, uma estrutura mais complexa, porque temos, na verdade, um espelho que fielmente refletirá a sua própria imagem deformada e outro espelho que deformará a sua própria imagem reproduzida fielmente. As imagens que surgirão infinitamente distintas neste curioso paralelismo especular preencherão as prateleiras intermináveis das bibliotecas, simbolizando todas as obras já existentes e também projetando aquelas que ainda se podem descobrir, como defendia Carlos Drummond de Andrade (ANDRADE, 2006, p. 248) no reino das palavras, onde estão as que esperam ser escritas. Assim, nos deparamos com uma construção de reflexos (e também, portanto, de leituras) infinitos e distintos, impossíveis de serem desenvolvidos em sua integridade. Seria esta, por sua vez, possivelmente, uma bela imagem da iminente falência da crítica diante da interminável multiplicação de sentidos de uma obra de arte.

$\mathrm{E}$, no entanto, seguimos otimistas rumo ao delicioso fracasso.

\section{Referências bibliográficas}

ANDRADE, C. D. Procura da poesia. In: . Antologia Poética. Rio de Janeiro: Record, 2006, p. 247-9.

BAKHTIN, M. Estética da Criação Verbal. Trad. P. Bezerra. São Paulo: Martins Fontes, 2003.

BARTHES, R. O Prazer do Texto. Trad. M. M. Barahona. Lisboa: Edições 70, 1974.

BORGES, J. L. Ficciones. Buenos Aires: Emecé, 1956. Kafka e seus precursores. In: . Obras Completas. Buenos Aires: Emecé, 1974, v. 4, p. 137-145.

ECO, U. Il nome della rosa. Milano: Bompiani, 1995.

Pós-escrito a Il nome della rosa. Trad. L. Z. Antunes e Á. Lorencini. Rio de Janeiro: Nova Fronteira, 1985.

. Sobre os espelhos. In . Sobre os espelhos e outros ensaios. Trad. B. Borges. Rio de Janeiro: Nova Fronteira, 1989, p. 11-37. 
CARROLL, L. Alice no País das Maravilhas/Alice no País do Espelho. Trad. M. Lobato. São Paulo: Brasiliense, 1972.

KRISTEVA, J. Introdução à semanálise. Trad. L. H. F. Ferraz. São Paulo: Perspectiva, 1974.

LOURENÇO, E. Jorge de Sena e o demoníaco. In: LISBOA, E. (org.) Estudos sobre Jorge de Sena. Lisboa: Imprensa Nacional/Casa da Moeda, 1984, p. 49-59. 